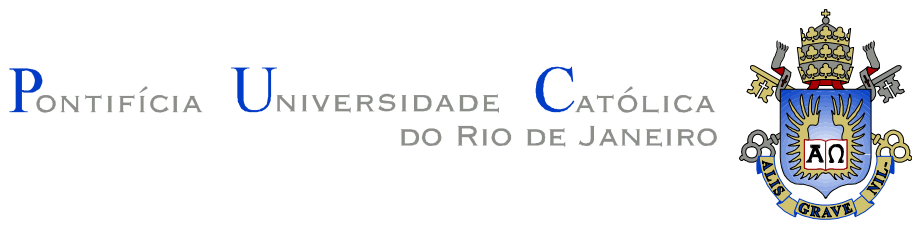

Carlos Enrique Tristá Aguilera

\title{
Aplicação de Métodos de Análise de Estabilidade de Taludes de Grande Altura em Mineração
}

Dissertação apresentada como requisito parcial para obtenção do grau de Mestre pelo Programa de Pós-graduação em Engenharia Civil da Puc-Rio. Aprovada pela Comissão Examinadora abaixo assinada:

Prof. Eurípedes do Amaral Vargas Jr. Orientador e Presidente Departamento de Engenharia Civil - PUC-Rio

Prof. Rodrigo Peluci de Figueiredo Co - orientador Universidade Federal de Ouro Preto - UFOP

Prof. Tácio Mauro P. de Campos Departamento de Engenharia Civil - PUC-Rio

Prof. Emilio Velloso Barroso Universidade Federal do Rio de Janeiro - UFRJ José Eugênio Leal Coordenador Setorial do Centro Técnico Científico - PUC-Rio 
Todos os direitos reservados. É proibida a reprodução total ou parcial do trabalho sem autorização da universidade, do autor e do orientador.

\section{Carlos Enrique Tristá Aguilera}

Graduou-se em Engenharia Civil em 2005 pela Universidad Católica del Norte, Antofagasta - Chile (UCN-Chile). Trabalhando atualmente na área de estabilidade de taludes de minas a céu aberto para a empresa A.Karzulovic e Asoc. Ltda. no Chile. Ingressou em 2007 no curso de mestrado em Engenharia Civil da Pontifícia Universidade Católica do Rio de Janeiro, na área de Geotecnia, desenvolvendo dissertação de mestrado na linha de pesquisa de Mecânica das Rochas.

Ficha Catalográfica

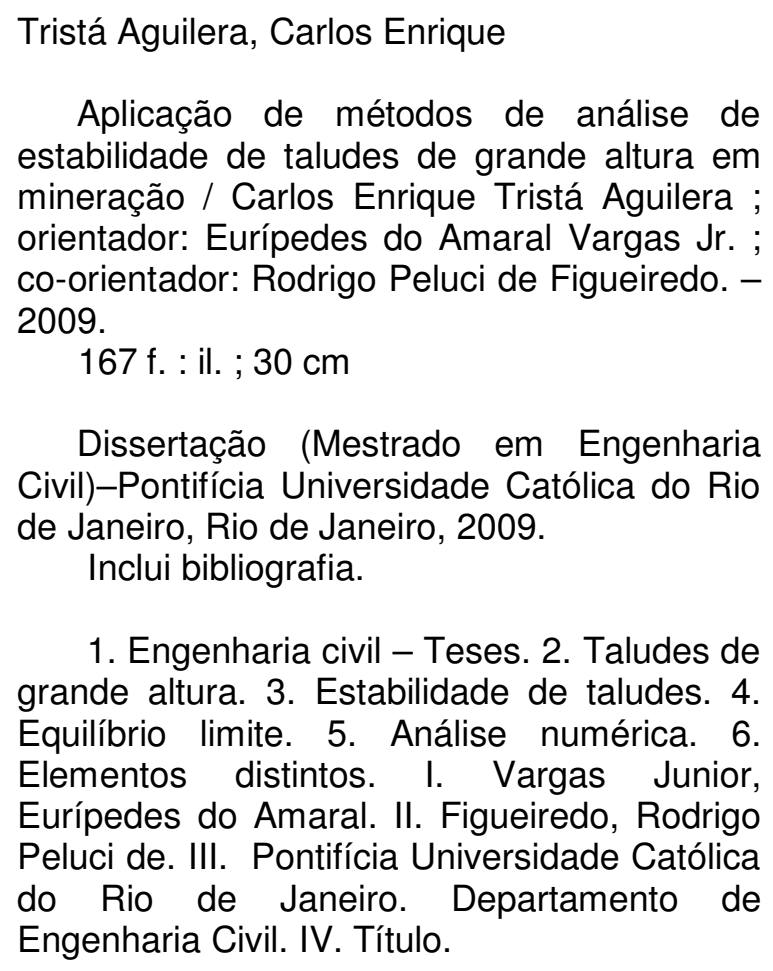
estabilidade de taludes de grande altura em mineração / Carlos Enrique Tristá Aguilera ; orientador: Eurípedes do Amaral Vargas Jr. ; co-orientador: Rodrigo Peluci de Figueiredo. 2009.

167 f. : il. ; $30 \mathrm{~cm}$

Dissertação (Mestrado em Engenharia Civil)-Pontifícia Universidade Católica do Rio de Janeiro, Rio de Janeiro, 2009.

Inclui bibliografia.

1. Engenharia civil - Teses. 2. Taludes de grande altura. 3. Estabilidade de taludes. 4. Equilíbrio limite. 5. Análise numérica. 6. Elementos distintos. I. Vargas Junior, Eurípedes do Amaral. II. Figueiredo, Rodrigo Peluci de. III. Pontifícia Universidade Católica do Rio de Janeiro. Departamento de Engenharia Civil. IV. Título.

CDD: 624 


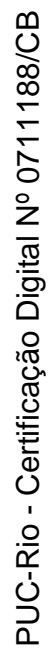

A Deus, por ter me dado força e saúde. 
Aos meus queridos pais: Maximo e Sara, por terem me dado educação, valores e um grande apoio durante toda a minha vida.

A minha Irmã por todo seu amor e compreensão durante toda sua vida. A minha avó que me apoio desde o início de meus estudos e hoje protege desde o céu. 


\section{Agradecimentos}

Aos Professores Eurípides Vargas Jr., Rodrigo Figueiredo, pela orientação e guia durante esta pesquisa.

Aos meus queridos pais, Maximo e Sara, pelo grande incentivo, mas torcendo muito pelo meu sucesso durante toda a minha vida de Universidade.

A CNPq pelo apoio Financeiro.

A minha Irmã: Danita pelo apoio e compreensão durante meus estudos do mestrado.

A minha avó Mamita Carmen por ter me acompanhado durante todos meus estudos e pelo incentivo de acabar sempre todo.

Aos meus professores, Eurípides Vargas Jr, Celso Romanel, Alberto Sayão, Sergio Fontoura, Franklin Antunes, pelos conhecimentos transmitidos, pela paciência que tiveram comigo e principalmente pelos inúmeros conselhos que me serão úteis por toda a vida.

Agradecer aos amigos que participaram na revisão da presente tese e apoiaram durante parte da minha estadia no Brasil: Raffaello, Felipe, Arthur, Carolina, Pamela, Sherryne.

Ao pessoal da empresa A. Karzulovic e Asoc Ltda, pelo apoio durante o desenvolvimento dessa dissertação, principalmente os senhores: Ricardo Sepulveda S., Zenny Espinoza, Cesar Villarroel e a senhorita Alejandra Boza.

Ao senhor Manuel Shellman, por torcer de continuar os estudos de mestrado até finalizar essa dissertação.

A secretária de pós-graduação Ana Roxo e Rita de Cássia pela grande ajuda paciência e amizade nestes anos de mestrado;

Meus sinceros agradecimentos a todas aquelas pessoas não citadas, mas que de alguma forma contribuíram para o sucesso deste trabalho. 


\section{Resumo}

Tristá Aguilera, Carlos Enrique; Vargas Jr., Eurípedes do Amaral; Figueiredo, Rodrigo Peluci de. Aplicação de Métodos de Análise de Estabilidade de Taludes de Grande Altura em Mineração. Rio de Janeiro, 2009. 170 p. Dissertação de Mestrado - Departamento de Engenharia Civil, Pontifícia Universidade Católica do Rio de Janeiro.

O presente trabalho apresenta a aplicação das metodologias de análise de estabilidade para taludes rochosos de grande altura comumente aplicados dentro do mundo da mineração. Mostra os principais fatores que influem dentro de uma análise de estabilidade como são a determinação das propriedades geomecânicas do maciço rochoso (rocha intacta e descontinuidades) e a caracterização geológica estrutural da região estudada. Esses parâmetros geralmente são obtidos a partir de ensaios de laboratório e de campo, além da informação que fornecem os mapeamentos geológicos. Outra forma de determinar estas propriedades de resistência é através de retro-análises em regiões onde tenha ocorrido algum tipo de colapso ou pela recopilação de dados que foram utilizados em análises anteriores e possam ser extrapolados. Também é apresentado um passo a passo das distintas etapas de um estudo de estabilidade e a obtenção de dados que finalizam na aplicação de softwares especializados na área de geotécnia e geomecânica, os quais permitirão determinar e pré-visualizar os possíveis problemas de instabilidade dentro dos taludes de um pit mineiro. Serão apresentados dois tipos de análises de estabilidade, o primeiro baseado na teoria do método de equilíbrio limite, o qual procura a possível superfície crítica de deslizamento dentro de um talude e que, condiciona a estabilidade da parede aos valores do fator de segurança. A segundo análise está relacionada com um modelo numérico, o qual aplica o método de elementos distintos ou de blocos, que permite a aplicação de um modelo constitutivo que descreva o comportamento dos materiais e das descontinuidades dentro do maciço rochoso, fornecendo como resultados a pré-visualização de variação de deslocamentos e vetores de velocidade para cada etapa de escavação.

\section{Palavras-chave:}

Taludes de grande altura, estabilidade de taludes, equilíbrio limite, analise numérica, elementos distintos. 


\section{Abstract}

Tristá Aguilera, Carlos Enrique; Vargas Jr., Eurípedes do Amaral; Figueiredo, Rodrigo Peluci de (Advisors). Application of Procedures for the Stability Analysis of High Slopes in Mining. Rio de Janeiro, 2009. 170 p. MSc. Dissertation - Department of Civil Engineering, Pontifícia Universidade Católica do Rio de Janeiro.

This thesis presents the application of procedures for the stability analysis of high slopes commonly applied in the mining world. It presents the main parameters that influence the stability analysis: determination of the rock mass geomechanical properties (intact rock and discontinuities) and the geological structures characterization of the studied region. These parameters generally are the result of laboratory and field tests, in addition, the information about the geological mapping. Another procedure for determining the properties' strength may be through a back analysis of a collapsed zone or extrapolation of a data compilation from previous analyses. Apart from strength parameter determination and concept applying of rock mechanics, this research describes step by step the different stages of a stability analysis and its obtained data, this work then finishes with a geotechnical and geomechanical software application, which will determines and previews slope stability problems for a mining pit. This thesis includes two stability analysis procedures: the first method applies the limit equilibrium theory, which looks for the critical failure surface that depends on depends on a factor of safety. The second one applies a numerical model that uses distinct element method, which through a constitutive model, describes how the materials and discontinuities behave in a rock mass, obtaining as a result, the displacement and velocity vectors for each excavation stage.

\section{Keywords}

Rock mass, slope stability, limit equilibrium, numerical analysis, distinct elements. 


\section{Índice}

1 Introdução 19

1.1. Generalidades 19

1.2. Objetivo do Trabalho de Pesquisa 21

1.3. Relevância do Trabalho de Pesquisa 22

1.4. Organização do Trabalho 24

2 Propriedades Geomecânica e Determinação dos Parâmetros de Resistência para a Análise de Estabilidade dos Taludes Rochosos de $\begin{array}{ll}\text { Grande Altura } & 25\end{array}$

2.1. Introdução 25

2.2. Caracterização Geomecânica de Taludes Rochosos 29

2.3. Determinação das Propriedades de Resistência 31

2.3.1. Resistência das Descontinuidades 31

2.3.2. Critério de Hoek-Brown Generalizado 39

2.4. Análise da Estabilidade de Taludes Rochosos de Grande Altura 48

3 Modos de Falhas em Taludes de Grande Altura 52

3.1. Generalidades 52

3.2. Modos de Falhas $\quad 54$

3.2.1. Falha por Cisalhamento de o tipo Planar 54

3.2.2. Falha por Cisalhamento do tipo Rotacional 54

3.2.3. Falha por Tombamento 56

3.3. Condições Gerais dos Tipos de Falha 57

4 Resumo dos Conceitos do Método de Equilíbrio Limite e Análise $\begin{array}{ll}\text { Numérica } & 61\end{array}$

4.1. Características do Método de Equilíbrio Limite 61

4.1.1. Conceito de Fator de Segurança 61

4.1.2. Conceito de Superfície de Falha 62 
4.1.3. Parâmetros Utilizados nas Análises de Equilíbrio Limite 62

4.1.4. Métodos de Equilíbrio Limite 62

4.1.5. Limitações do Método de Equilíbrio Limite 63

4.1.6. Método das Lamelas ou "Slices" (Abramson et al. 1995) 63

4.2. Análise Numérica $\quad 70$

4.2.1. Modelos Contínuos $\quad 74$

4.2.2. Modelos Descontínuos $\quad 74$

4.2.3. Fatores Influentes dentro da Modelagem Numérica 75

5 Análise de Estabilidade para a Etapa de Exploração “Etapa8” da Mina Zaldivar. Aplicação de um Modelo de Equilíbrio Limite e um Modelos Numérico 79

5.1. Características Geológicas da Jazida (Hormazaval et al., 2003) 79

5.1.1. Unidades Litológicas 79

5.1.2. Alteração Mineralógica 81

5.1.3. Composição Mineralógica 82

5.2. Caracterização Geológica Estrutural 83

5.2.1. Generalidades 83

5.2.2. Caracterização Geológica Estrutural da Mina Zaldivar 89

5.2.2.1. Domínios Estruturais 89

5.2.3. Propriedades Geotécnicas 97

5.2.3.1. Resistência ao Cisalhamento das Descontinuidades 97

5.2.3.2. Propriedades Geotécnicas do Maciço Rochoso 99

5.3. Análise de Estabilidade mediante o Método de Equilíbrio Limite 106

5.3.1. Resistência Direcional para o Maciço Rochoso 106

5.3.2. Análise ao Nível Inter-rampa e Global dos Taludes 114

5.3.2.1. Detalhe da Análise para a Seção XSO2 (zona de colapso) 116

5.4. Análise Retrospectivo de Instabilidades devido a Estruturas Não

$\begin{array}{ll}\text { Aflorantes } & 126\end{array}$

5.4.1. Generalidades 126

5.4.2. Cálculo das Propriedades de Resistência do Maciço Rochoso 128

5.5. Análise de Estabilidade para uma Nova Caracterização Geológica

Estrutural 
5.6. Análise Numérica (UDEC Version 4.0, Itasca 2004) 136

5.6.1. Generalidades (UDEC Version 4.0 Manual, 2004) 136

5.6.2. Modelagem Numérica 137

5.6.3. Resultados do Modelo Numérico 141

6 Conclusões e Sugestões 150

6.1. Conclusões 150

6.2. Sugestões 152

7 Referências Bibliográficas 153

$\begin{array}{ll}\text { A. Anexo } & 157\end{array}$ 


\section{Lista de Figuras}

Figura 1.1 - Localização geográfica Mina Zaldivar. ....................................... 20

Figura 1.2 - Exemplo de deslizamento de uma descontinuidade não aflorante. ...23

Figura 2.1 - Geometria dos taludes mineiros. (Duncan, C. W. e Christopher, W.

M., 2004) 27

Figura 2.2 - Critério de ruptura de Patton. Trajetória bilinear de ruptura.............. 34

Figura 2.3 - Perfis de rugosidade na superfície da junta e o valor JRC correspondente (Barton and Choubey 1977).

Figura 2.4 - Caracterização da rugosidade nas descontinuidades segundo as recomendações da ISRM (1978). (modificada de Brown (1981))................ 38

Figura 2.5 - Relação entre as tensões principal maior e principal menor de Hoek e Brown e sua equivalência com o critério de Mohr-Coulomb. .46

Figura 3.1 - Falhas rotacionais e combinação de falhas do tipo rotacional com falhas planas (Hoek e Bray, 1981) 55

Figura 4.1 - Divisão em lamelas ou "slices" de uma potencial massa de deslizamento. .64

Figura 4.2 - Divisão Forças agindo sobre uma lamela ou "slice". 64

Figura 5.1 - Unidades litológicas nas paredes da Etapa 8 do "pit” da Mina Zaldivar.

Figura 5.2 - Mapeamento de set de estruturas. Espaçamento real e aparente de um set de estruturas. 85

Figura 5.3 - Efeito da correção de Terzaghi na definição dos contornos de concentração de pólos de estruturas intermédias. .86

Figura 5.4 - Significado do coeficiente de Fisher K. (Diederishs, 1990). 90

Figura 5.5 - Determinação do cálculo da probabilidade de ocorrência numa esfera para os pontos normais projetados.

Figura 5.6 - Distribuição areal dos domínios estruturais presentes na Etapa 8 da Mina Zaldivar. .93

Figura 5.7 - Localização das Falhas Maiores ou Falhas na Escala Mina, atualmente reconhecidas nas paredes da Etapa 8 da Mina Zaldivar. 96

Figura 5.8 - Trajetória de falha e estrutura equivalente dentro de um maciço 
rochoso. 98

Figura 5.9 - Efeitos da presença de um (a) duas e uma série de descontinuidades (b) com diferentes orientações na resistência de uma amostra de rocha (Hoek \& Brown, 1980). 108

Figura 5.10 - Gráficos de resistência direcional. Efeitos dos sets de descontinuidade paralelos ao talude na resistência ao cisalhamento do maciço rochoso. A magnitude da resistência para uma orientação $\theta$, é igual à distância radial desde a origem até a curva vermelha. 109

Figura 5.11 - Representação do efeito das pontes de rocha (modificado por Wittke, 1990). 109

Figura 5.12 - Superfície de falha do tipo "step-path" e a estrutura ou descontinuidade equivalente para um talude de rocha que contem um set de descontinuidades (lado esquerdo) e dois sets (lado direito), para um talude com descontinuidades não persistentes mergulhando paralelo à face do talude.

Figura 5.13 - Falha de tipo planar através de juntas e pontes de rochas dentro de um talude de rocha com uma altura $H$ e inclinação $\beta$. As pontes de rochas têm um comprimento de $l_{r}$, e a descontinuidade $l_{j}$ e um ângulo de mergulho aparente de $\alpha_{a}$ 110

Figura 5.14 - Definição do set de direções onde, a resistência do maciço rochoso é igual à resistência na descontinuidade (no caso de descontinuidades persistentes) ou igual à resistência da "estrutura ou descontinuidade equivalente" (no caso de descontinuidades não persistentes dentro do maciço rochoso), em termos da inclinação do mais provável ângulo aparente da descontinuidade na seção do talude, $\alpha_{a}$, e a correspondente variação, $\Delta \alpha_{a}$. A área corresponde à "Zona Frágil” dentro da resistência direcionar do maciço rochoso.

Figura 5.15 - Definição da "zona de transição" que inclui os efeitos de uma zona de alteração associada com uma descontinuidade com a mais provável inclinação do ângulo de mergulho de $\alpha_{a}$

Figura 5.16 - Definição da resistência direcional de um maciço rochoso que contem dois sets de descontinuidades. As descontinuidades do Set 1 são não persistentes e incluem pontes de rochas (maior resistência). As 
descontinuidades do Set 2 são persistentes e tem uma zona de alteração associada com elas.

Figura 5.17 - Seções analisadas para determinar a estabilidade dos taludes em nível inter-rampa e global.

Figura 5.18 - Deslizamento da bancada devido afloramento da Falha Colorada.116

Figura 5.19 - Mecanismo de falha na parede Sul da mina Zaldivar. 117

Figura 5.20 - Seção analisada XSO2, Etapa 8, mina Zaldivar. 118

Figura 5.21- Análise do talude Global para a Seção XS02.

Figura 5.22 - Análise do talude nível Inter-rampa para a Seção XS02. 123

Figura 5.23 - Análise do talude nível da falha para a Seção XS02. 124

Figura 5.24 - Deslizamento pela combinação junta ou falha menor combinada com a ponte de rocha. 125

Figura 5.25 - Esquema que apresenta a forma de como uma zona de material frágil ou baixa qualidade geotécnica possibilita o deslizamento de um plano ou cunha não aflorante na cara do talude.

Figura 5.26 - Esquema que apresenta a forma da análise de um plano que não aflora, mas segue definido por uma zona de baixa qualidade geotécnica, "zona frágil”..... 128

Figura 5.27 - Geometria para a primeira etapa de análise. 129

Figura 5.28 - Valores da geometria utilizada na Primeira Etapa da análise retroativa. 129

Figura 5.29 - Análise com software ROCPLANE para determinar o valor da força $\mathrm{F}$, a qual sustentam a parte superior do plano de deslizamento. 130

Figura 5.30 - Forças agindo na parte inferior do plano não aflorante. 130

Figura 5.31 - Seção XS02 modificada em base a nova caracterização geológica estrutural. 133

Figura 5.32 - Análise global da seção XS02. O talude não indica problemas de instabilidade. 134

Figura 5.33 - Instabilidade que se apresenta no nível inter-rampa na parede na seção XS02. 135

Figura 5.34 - Instabilidade que se apresenta no nível de bancadas na parede na seção XS02.

Figura 5.35 - Interpretação para examinar e determinar a estabilidade de um 
talude. (UDEC Version 4.0, Manual, Itasca, 2004).

Figura 5.36 - Materiais ou unidades geotécnicas definidas por grupos de blocos para a seção XS02 aplicando o software UDEC (Itasca, 2004)...

Figura 5.37 - Zonas plastificadas e de falha por tração na Etapa de Escavação 2 do talude da seção XSO2 derivadas do analise com o software UDEC (Itasca, 2004).

Figura 5.38 - Um zoom das zonas plastificadas e de falha por tração na Etapa de Escavação 2 do talude da seção XSO2 derivadas do analise numérica com o software UDEC (Itasca, 2004). 144

Figura 5.39 - Deslocamentos localizados no pé do talude depois da Etapa de Escavação 2 do talude da seção XSO2, e que alcançam aproximadamente 35 cm., derivadas do analise numérica com o software UDEC (Itasca, 2004). 145

Figura 5.40 - Aumento e ordenamento dos vetores de velocidade concentrados no pé do talude depois da Etapa de Escavação 2 do talude da seção XSO2, com um valor de $5.404 \mathrm{e}-3 \mathrm{~m} / \mathrm{sg}$. derivadas do analise numérica com o software UDEC (Itasca, 2004).

Figura 5.41 - Indicador de zonas plastificadas. Falhas no nível do talude por tração e deslizamentos das estruturas representadas pelo modelo de ubiquitas. $\mathrm{Na}$ zona superior do talude observa se a geração de uma trinca de tração, resultados obtido logo da terceira etapa de escavação do analise numérica com o software UDEC (Itasca, 2004).

Figura 5.42 - Indicador de zonas plastificadas. Um zoom nas de falhas no nível do talude por tração e deslizamentos das estruturas representadas pelo modelo de ubiquitas. Na zona superior do talude observa se a geração de uma trinca de tração, resultados obtido logo da terceira etapa de escavação do analise numérica com o software UDEC (Itasca, 2004).

Figura 5.43 - Deslocamento no eixo X, situação de instabilidade no nível do talude, marcados por os maiores deslocamentos no pé da escavação. 148

Figura 5.44 - Ordenamento e aumento dos vetores de velocidade indicando uma situação de instabilidade no nível do talude.

Figura A.1 - Indicador das zonas de plasticidade para a primeira etapa de escavação. Como resultado o modelo não fornece indicadores de algum tipo de falha ou formação de superficies de deslizamento..... 
Figura A.2 - Vetores de deslocamento para a primeira etapa de escavação. Os vetores não indicam grandes valores de deslocamento, o que implica uma situação de estabilidade logo da primeira etapa de escavação 158

Figura A.3 - Vetores de deslocamento para a primeira etapa de escavação. Os vetores não indicam grandes valores de deslocamento, o que implica uma situação de estabilidade logo da primeira etapa de escavação 158

Figura A.4 - Vetores de velocidade para a primeira etapa de escavação. Os vetores não indicam grandes não apresentam um ordenamento nem valor que indique algum tipo de instabilidade logo da primeira etapa de escavação

Figura A.5 - O indicador de plasticidade logo da segunda etapa de escavação, manifesta zonas de falha por tração no nível da bancada e zonas de deslizamento, alem do desenvolvimento da trinca de tração no topo do talude

Figura A.6 - Os vetores de deslocamentos começam a ter um ordenamento e um aumento das magnitudes, manifestando uma instabilidade local no nível da bancada inferior

Figura A.7 - Os deslocamentos em X aumentam ate magnitudes de $35 \mathrm{~cm}$, novamente manifestando instabilidades localizadas no nível das bancadas logo da segunda etapa de escavação 160

Figura A.8 - O ordenamento dos vetores de velocidade e a magnitude deles, segundo os parâmetros impostos pela Itasca, manifestam problemas de instabilidade localizadas no nível das bancada inferior logo da segunda etapa de escavação

Figura A.9 - O indicador de plasticidade logo da terceira etapa de escavação, manifesta zonas de falha por tração, zonas de desenvolvimentos de superfícies de deslizamento e deslizamento através dos sistemas de ubiquitas, todas elas nível do talude. Também o modelo fornece do desenvolvimento de uma trinca de tração no topo do talude. 161

Figura A.10 - Os vetores de deslocamento manifestam um ordenamento e magnitudes que indicam problemas de instabilidade no nível do talude logo da terceira etapa de escavação

Figura A.11 - Os deslocamentos em $\mathrm{X}$ fornecem magnitudes que indicam problemas de instabilidade no nível do talude, principalmente na bancada 
inferior onde o valor alcança os $60 \mathrm{~cm}$. logo da terceira etapa de escavação 162

Figura A.12 - Vetores ordenados e com uma magnitude da ordem do 1e-03 indicam problemas de instabilidade no nível do talude logo da terceira etapa de escavação

Figura A.13 - Indicador das zonas plastificadas logo da quarta etapa de escavação mostra zonas de falha por tração nos taludes inferiores e desenvolve uma superfície de deslizamento perto da zona da falha Colorada.

Figura A.14 - Vetores de deslocamentos têm maior magnitude na base do talude, indicando onde se encontram os maiores problemas de instabilidade logo da quarta etapa de escavação 164

Figura A.15 - Os deslocamentos em $\mathrm{X}$ na base do talude indicam onde se encontram os maiores problemas de instabilidade logo da quarta etapa de escavação 164

Figura A.16 - Vetores de velocidade indicam um ordenamento e magnitudes na base do talude que indicam uma instabilidade localizada principalmente nessa zona..... 165

Figura A.17 - A quinta etapa de escavação não apresenta grandes zonas de falha por tração. $\mathrm{O}$ indicador mostra zonas de deslizamento perto da falha Colorada 165

Figura A.18 - Os vetores de deslocamentos mostram uma estabilidade no nível do talude, mas ainda existem deslocamentos que possam se considerar como uma instabilidade no nível local (bancada inferior) 166

Figura A.19 - Os deslocamentos no eixo X logo da quinta etapa de escavação demonstram uma instabilidade localizada principalmente na base no talude 166

Figura A.20 - Os vetores de velocidade indicam movimentos no talude, mas a magnitude destes não são suficiente como para gerar uma instabilidade no nível do talude. 167 


\section{Lista de Tabelas}

Tabela 2.1- Descrição da Competência da rocha e campos estimados da Resistência 'a Compressão Uniaxial (UCS). (Modificada de Brown

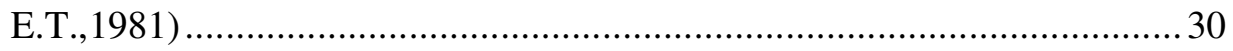

Tabela 2.2 -. Valores típicos de $\mathrm{c}$ e $\phi_{b}$ para rocha intacta (Dados selecionados de Walthan (1999), Rahn (1986), Goodman (1989), Farmer (1968), Jimenez Salas e Justo Alpanes (1975)...... 36

Tabela 2.3 - Valores da constante $\mathrm{m}_{\mathrm{i}}$ para rocha intacta, por grupo de rocha

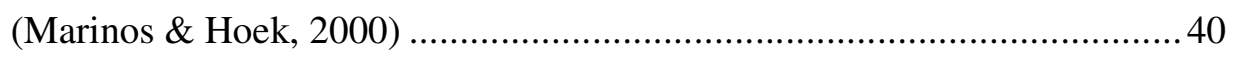

Tabela 2.4 - Determinação do valor GSI (Marinos et al., 2005).

Tabela 2.5 - Estimativa de GSI para maciços rochosos heterogêneo (Marinos et al. 2005) 43

Tabela 2.6 - Orientações para a escolha do valor $D$ (Hoek et al., 2002). 44

Tabela 2.7 - Resumo das características e aplicações de cada um dos métodos numéricos...

Tabela 4.1- Equações e incógnitas associadas com o Método das Lamelas ou "Slices".

Tabela 4.2 - Condições de Equilíbrio Estático Satisfeita pelos Métodos de Equilíbrio Limite. (Abramson et al, 2002)

Tabela 5.1 - Unidades litológicas presentes na Etapa 8 da Mina Zaldivar ( Hormazabal et al., 2003) 80

Tabela 5.2 - Descrição dos diferentes tipos de alterações reconhecidas nas paredes dos taludes do "pit" da mina Zaldivar. 82

Tabela 5.3 - Descrição da composição mineralógica localizada na jazida Zaldivar.

Tabela 5.4 - Tipos de estruturas segundo sua origem. …............................... 88

Tabela 5.5 - Domínios estruturais para a Etapa 8 da mina Zaldivar. .94

Tabela 5.6 - Ângulos de mergulho e direção de mergulho por domínio estrutural dentro da Etapa 8 da mina Zaldivar. 95

Tabela 5.7 - Falhas a escala mina para a Etapa 8 da mina Zaldivar. 96 
Tabela 5.8 - Resistência ao Cisalhamento das distintas descontinuidades.

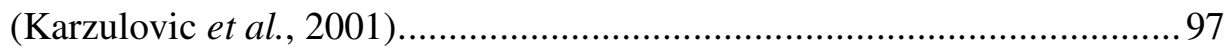

Tabela 5.9 - Propriedades das distintas unidades geotécnicas pertencente aos taludes da mina Zaldivar para a Etapa 8............................................... 103

Tabela 5.10 - Propriedades das distintas unidades geotécnicas pertencente aos taludes da mina Zaldivar para a Etapa 8 ................................................. 104

Tabela 5.11 - Propriedades das distintas unidades geotécnicas pertencente aos taludes da mina Zaldivar para a Etapa 8............................................... 105

Tabela 5.12 - Propriedades de Resistência Direcionar ao Cisalhamento............ 119

Tabela 5.13 - Propriedades de Resistência Direcionar ao Cisalhamento............ 120

Tabela 5.14 - Propriedades de Resistência ao Cisalhamento segundo o Critério de Ruptura de Mohr-Coulomb. ................................................................ 121

Tabela 5.15 - Propriedades de Resistência ao Cisalhamento da Falha ao Nível de Mina. 121

Tabela 5.16 - Resultados da análise de estabilidade seção XSO2. 122

Tabela 5.17 - Resultados de propriedades de resistência segundo análise retroativa.

Tabela 5.18 - Propriedades de resistência de unidades geotécnicas para a análise em SLIDE (2005). 132

Tabela 5.19 - Resultados do análise numérica através do software UDEC (Itasca, 2004) 